\title{
A Novel p75 Neurotrophin Receptor-Related Protein, NRH2, Regulates Nerve Growth Factor Binding to the TrkA Receptor
}

\author{
Simon S. Murray, ${ }^{1}$ Pilar Perez, ${ }^{3}$ Ramee Lee, ${ }^{2}$ Barbara L. Hempstead, ${ }^{2}$ and Moses V. Chao ${ }^{1}$ \\ ${ }^{1}$ Skirball Institute of Bimolecular Medicine, New York University School of Medicine, New York, New York 10016, ${ }^{2}$ Division of Hematology, Weill Medical \\ College of Cornell University, New York, New York 10021, and 3'Instituto de Microbiologia Bioquimica, Departamento de Microbiologia y Genetica, Consejo \\ Superior de Investigaciones Científicas, Universidad de Salamanca, 37007 Salamanca, Spain
}

Nerve growth factor (NGF) functions as a ligand for two receptors, the TrkA tyrosine kinase receptor and the p75 neurotrophin receptor $\left(\mathrm{p} 75^{\mathrm{NTR}}\right)$. The Ig-like domains of Trk receptors and the cysteine-rich repeats of $\mathrm{p} 75^{\mathrm{NTR}}$ are involved in binding to the neurotrophins. Recently, a closely related gene to $75^{\mathrm{NTR}}$ called neurotrophin receptor homolog-2 (NRH2) was identified; however, the function of NRH2 and its relevance to neurotrophin signaling are unclear. $\mathrm{NRH} 2$ contains a similar transmembrane and intracellular domain as p $75^{\mathrm{NTR}}$ but lacks the characteristic cysteine-rich repeats in the extracellular domain. Here we show that NRH2 is expressed in several neuronal populations that also express $75^{\mathrm{NTR}}$ and Trk receptors. NRH2 does not bind to NGF; however, coimmunoprecipitation experiments demonstrate that NRH2 is capable of interacting with TrkA receptors. Coexpression of NRH2 with TrkA receptors resulted in the formation of high-affinity binding sites for NGF. These results indicate that a transmembrane protein related to p $75^{\mathrm{NTR}}$ is capable of modulating Trk receptor binding properties.

Key words: neurotrophin; receptor; high-affinity binding; p75; NGF; Trk

\section{Introduction}

Neurotrophins are unique in exerting their cellular effects through the actions of two different receptors, the Trk receptor tyrosine kinase and the $\mathrm{p} 75$ neurotrophin receptor $\left(\mathrm{p} 75^{\mathrm{NTR}}\right)$, a member of the tumor necrosis factor (TNF) receptor superfamily (Kaplan and Miller, 2000; Huang and Reichardt, 2001; Hempstead, 2002). The three Trk receptors TrkA, TrkB, and TrkC bind specifically to NGF, BDNF, and neurotrophin-3 (NT-3), respectively. NT-4 also serves as a ligand for TrkB. Trk receptors consist of an extracellular ligand binding region consisting of Ig-C2 domains, a single transmembrane domain, and a highly conserved intracellular tyrosine kinase domain. There are no sequence similarities between Trk and p75 receptors in either their ligand binding or cytoplasmic domains. The p75 receptor contains an unusually high number of negatively charged residues embedded within four cysteine-rich repeats in the ectodomain. All neurotrophins are capable of binding to this region of the 75 receptor. In addition to a single transmembrane domain, $\mathrm{p} 75^{\mathrm{NTR}}$ also contains a cytoplasmic death domain.

Studies in Xenopus laevis have indicated the existence of a gene

Received Aug. 27, 2003; revised Dec. 3, 2003; accepted Jan. 12, 2004.

We thank Scott Thomas and Gus Khursigara for assistance, Kenneth Teng for superior cervical ganglion cultures and staining, Rory Curtis and Pete DiStefano for providing sequence information on NRH2, and Trevor Kilpatrick for ongoing support. This work was supported by National Institute of Neurological Disorders and Stroke Grant NS21072, National Cancer Institute Grant CA56490, and Multiple Sclerosis Australia. S.S.M. is currently supported by a Postdoctoral Fellowship from Multiple Sclerosis Australia.

Correspondence should be addressed to Simon Murray, Multiple Sclerosis Research Group, Howard Florey Institute, National Neurosciences Facility, Level 2, 161 Barry Street, Carlton South, Victoria 3053, Australia. E-mail: s.murray@hfi.unimelb.edu.au.

DOI:10.1523/JNEUROSCI.3960-03.2004

Copyright $\odot 2004$ Society for Neuroscience $\quad 0270-6474 / 04 / 242742-08 \$ 15.00 / 0$ structurally related to $\mathrm{p} 75^{\mathrm{NTR}}$, the neurotrophin receptor homolog (NRH) (Hutson and Bothwell, 2001). NRH is homologous to $\mathrm{p} 75^{\mathrm{NTR}}$, displaying strong sequence similarity in the transmembrane, juxtamembrane, and death domain regions (Kanning et al., 2003). Interestingly, two NRH genes ( $x$ NRH1a and $x$ NRH $1 b$ ) exist in Xenopus. The Xenopus NRH1 contains the signature features for a TNF receptor member, including four cysteine-rich repeating elements in the extracellular domain. However, in the mammalian genome, sequences corresponding to the NRH1 gene do not exist. Instead, a closely related gene, $\mathrm{NRH} 2$, has been found. NRH2 contains a truncated extracellular domain but retains the transmembrane and cytoplasmic sequences that display high similarity to $\mathrm{p} 75^{\mathrm{NTR}}$. NRH2 has been identified recently in rat and been alternatively termed PLAIDD (p75-like apoptosis inducing death domain protein) (Frankowski et al., 2002) and also NRADD (neurotrophin receptor alike death domain protein) (Wang et al., 2003).

The finding of a closely related gene to $\mathrm{p} 75^{\mathrm{NTR}}$ raises several questions. First, is NRH2 expressed in neurotrophin-responsive cells? Does NRH2 play any role in neurotrophin function, although it lacks a significant part of the ligand binding domain? To address these questions, we studied the pattern of expression of $\mathrm{NRH} 2$ protein in several tissues in the developing rat. Because p $75^{\text {NTR }}$ is known to exert effects on Trk receptor function (Hempstead, 2002; Roux and Barker, 2002), the NRH2 protein was assessed for its ability to interact with the Trk receptors. In this study, we find that NRH2 is expressed in spinal motor neurons, sympathetic neurons, sensory neurons of the dorsal root ganglion, and retinal cells. We find that $\mathrm{NRH} 2$ associates with TrkA receptors and enhances NGF binding to TrkA. Interestingly, this ability does not depend on direct binding of NGF to 
$\mathrm{NRH} 2$, indicating the transmembrane and juxtamembrane regions of $\mathrm{NRH} 2$ may serve a similar function to the $\mathrm{p} 75$ receptor.

\section{Materials and Methods}

Preparation of NRH2 antibody. A glutathione S-transferase (GST) fusion protein containing the intracellular domain of the mouse NRH2 (amino acids 83-228) was generated in the pGEX-6 vector using a PCR strategy, followed by subcloning into Bam H1 and EcoR1 restriction sites. Rabbit polyclonal antisera was subsequently generated (Cocalico Biologicals, Reamstown, PA) and affinity purified on GST-glutathione columns.

Immunohistochemistry. Tissues from neonatal rat pups (postnatal days $2-3$ ) were postfixed in Bouin's fixative overnight at $4^{\circ} \mathrm{C}$ and then processed for paraffin embedding. Sections 5- to 12- $\mu$ m-thick were cut on a microtome and then dewaxed in preparation for staining. Sections were briefly rinsed in PBS. Endogenous peroxidase activity was quenched by incubation in a $3 \%$ solution of $\mathrm{H}_{2} \mathrm{O}_{2}$ in methanol at $4^{\circ} \mathrm{C}$ for $20 \mathrm{~min}$. After rinsing in PBS, sections were permeabilized in $0.04 \%$ Triton X-100 in PBS for $15 \mathrm{~min}$, rinsed in PBS again, and then blocked in 5\% powdered milk and 5\% normal goat serum in PBS for $1 \mathrm{hr}$ at room temperature. After three rinses in PBS, sections were incubated with primary antibodies against $75^{\text {NTR }}$ (9651 antibody, 1:5000), NRH2 (1074 antibody, 1:500), or pan-Trk (C-15, 1:500; Santa Cruz Biotechnology, Santa Cruz, $\mathrm{CA}$ ) in $5 \%$ normal goat serum in PBS at $4^{\circ} \mathrm{C}$ overnight. Sections were again rinsed in $\mathrm{PBS}$ and exposed to biotinylated goat anti-rabbit antibodies (1:200; Vector Laboratories, Burlingame, PA). After three additional rinses in PBS, sections were incubated with avidin-biotin conjugated to peroxidase following the protocol of the manufacturer (Vector Laboratories standard kit, PK-400). Immunreactivity was visualized using 0.05\% 3,3-diaminobenzidine tetrahydrochloride (Daco) in PBS buffer containing $0.03 \% \mathrm{H}_{2} \mathrm{O}_{2}$ and nickel chloride to enhance the signal. Sections were subsequently dehydrated and coverslipped using DePeX. Control sections were processed in an identical manner but incubated with preimmune serum (1:500 dilution) from the rabbit inoculated against NRH2.

Primary cell culture and immunocytochemistry. Cultures of pure sympathetic neurons from the superior cervical ganglion of postnatal day 1 mice were prepared and maintained in culture for $5 \mathrm{~d}$ as described previously (Bamji et al., 1998) and then fixed in 3\% paraformaldehyde. For immunofluorescent detection, cells were permeablized and incubated with the polyclonal antisera raised against NRH2 (1074 antibody, 1:100) or anti-p75 (9992 antibody, 1:100) and with a monoclonal anti-Trk antibody (B-3, 1:100; Santa Cruz Biotechnology) as indicated.

Cell lines and mammalian expression vectors. The cDNA expression vectors for the full-length rat TrkA, TrkB, TrkC, and TrkA cytoplasmic deletion constructs have been described previously (Yano et al., 2001), as has the full-length rat $\mathrm{p} 75^{\mathrm{NTR}}$ vector (Khursigara et al., 2001). The mouse NRH2 construct was a gift from Millennium Pharmaceuticals (Cambridge, MA) (Rory Curtis) and was subcloned into the pFlagCMV1 expression vector (Sigma, St. Louis, MO). PC12-615 cells and the human embryonic kidney cell line HEK293 was maintained and cultured as described previously (Yano et al., 2001).

Transfection and immunoprecipitation in mammalian cells. HEK293 cells were cotransfected with the Trk, p75 ${ }^{\text {NTR }}$, or NRH2 constructs using the calcium phosphate precipitation method. After $24-36 \mathrm{hr}$ in culture, whole-cell lysates were prepared. Briefly, cells were lysed in TNE buffer (Tris- $\mathrm{HCl}$ buffer, $\mathrm{pH} 7.6$, containing 1\% NP-40, $150 \mathrm{~mm} \mathrm{NaCl}$, and $1 \mathrm{~mm}$ EDTA), containing protein inhibitors $(3.8 \mu \mathrm{g} / \mathrm{ml}$ aprotinin, $1 \mu \mathrm{g} / \mathrm{ml}$ leupeptin, $1 \mathrm{~mm}$ PMSF, $2 \mathrm{~mm} \mathrm{NaF}$, and $\left.1 \mathrm{~mm} \mathrm{Na}_{3} \mathrm{VO}_{4}\right)$, kept on ice for 15 min, and centrifuged at $14,000 \mathrm{rpm}$ at $4^{\circ} \mathrm{C}$ for $15 \mathrm{~min}$, and then the protein lysate was transferred to a fresh tube. After lysis, protein content was determined by the Bio-Rad (Hercules, CA) assay using bovine serum albumin as a standard. Equal amounts of total protein were immunoprecipitated overnight at $4^{\circ} \mathrm{C}$. The anti-Flag M2 antibody (mouse monoclonal F-3165; Sigma) was used for all immunoprecipitations. Antibodies were then precipitated with $20 \mu$ l of Protein G agarose (Roche Products, Hertforshire, UK) for $2 \mathrm{hr}$ at $4^{\circ} \mathrm{C}$, washed seven times in TNE buffer, eluted in standard Laemmli protein loading buffer, boiled for $5 \mathrm{~min}$, loaded and separated on an SDS-PAGE gel, and transferred to polyvinylidene difluoride (PVDF) overnight. The level of expression of native pro- teins was determined using whole-cell lysates in Western blot analysis. PVDF membranes were blotted for the presence of immunoprecipitated complexes and native proteins with the following: anti-p75 (9992 antibody); anti-TrkA [ H-190 antibody (Santa Cruz Biotechnology) or AB1577 antibody (Chemicon, Temecula, CA)]; anti-pan Trk (C-14 antibody; Santa Cruz Biotechnology); and anti-Flag (F-3165 antibody; Sigma). Immunocomplexes were detected by the enhanced chemiluminescence technique (Amersham Biosciences, Arlington Heights, IL).

Cross-linking analysis. Mouse NGF (renin free; Harlan Bioproducts for Science, Indianapolis, IN) was radioiodinated using lactoperoxidase and hydrogen peroxide as described previously (Mahadeo et al., 1994). The specific activity averaged $3000 \mathrm{dpm} / \mathrm{fmol}$ and was used within 1 week of radioiodination. The cross-linking binding assay used transiently transfected HEK293 cells. Cells were plated and transfected with pcDNA3p75, pFlag-CMV1-NRH2, or both, using the Lipofectamine 2000 reagent following the protocol of the manufacturer. A small amount of pEGFP (Clontech, Cambridge, UK) was cotransfected at all times to ensure the efficacy of transfection. The following day, cells were harvested in PBS containing $1 \mathrm{~mm}$ EDTA, divided, and replated at a lower density. Twentyfour hours later, cells were harvested again, resuspended in PBS containing $1 \mathrm{mg} / \mathrm{ml} \mathrm{BSA}$ and $1 \mathrm{mg} / \mathrm{ml}$ glucose, and adjusted to a final concentration of $\sim 2 \times 10^{6}$ cells $/ \mathrm{ml}$. Transfected cell suspensions were subjected to incubation with ${ }^{125} \mathrm{I}-\mathrm{NGF}$, followed by cross-linking and immunoprecipitation analysis. ${ }^{125} \mathrm{I}-\mathrm{NGF}$ was added to a final concentration of $1-2 \mathrm{ng} / \mathrm{ml}$ and incubated for $2 \mathrm{hr}$ at $4^{\circ} \mathrm{C}$. Cross-linking of ligand to receptor complex(es) was achieved by the addition of the cross-linking agents 1-ethyl-3-(3-dimethylaminopropyl) carbodiimide hydrochloride (EDAC) (Pierce, Rockford, IL) at a final concentration of $4 \mathrm{~mm}$ and disuccinimidyl suberate (DSS) (Pierce) at a concentration of $25 \mu \mathrm{M}$ as described previously (Hempstead et al., 1991; Huber and Chao, 1995). To quench the reaction, cells were centrifuged at $1500 \mathrm{rpm}$ for $5 \mathrm{~min}$ at $4^{\circ} \mathrm{C}$ and rinsed three to four times in PBS containing $50 \mathrm{~mm}$ lysine. Samples were lysed in a buffer that contained $10 \mathrm{~mm}$ Tris, $\mathrm{pH}$ 7.4, $66 \mathrm{~mm}$ EDTA, $1 \%$ Nonidet P-40, and $0.4 \%$ deoxycholate in the presence of $1 \mathrm{~mm}$ aprotinin, $1 \mathrm{~mm}$ leupeptin, and $1 \mathrm{~mm}$ PMSF. After incubation with specific antisera [anti-Flag (mouse monoclonal F-3165 antibody; Sigma), anti-p75 (9992 antibody), or anti-NGF (M-20 antibody; Santa Cruz Biotechnology)] overnight at $4^{\circ} \mathrm{C}$, samples were incubated with Protein $\mathrm{A}$ Sepharose $(50 \mu \mathrm{g} / \mathrm{ml})$ for $1 \mathrm{hr}$ at $4^{\circ} \mathrm{C}$, washed extensively in $10 \mathrm{~mm}$ Tris, pH 8, $150 \mathrm{~mm} \mathrm{NaCl}, 10 \mathrm{~mm} \mathrm{KCl}, 0.4 \%$ deoxycholate, $1 \%$ Nonidet P-40, and $1 \mathrm{~mm}$ EDTA, and subjected to SDS-PAGE. The immunoprecipitated products were visualized by autoradiography.

Equilibrium binding assay. The equilibrium binding assay also used transiently transfected HEK293 cells. Cells were plated and transfected with pcDNA3-TrkA or both pcDNA3-TrkA and pFlag-CMV1-NRH2 constructs at a ratio of 1:6, respectively, using the Lipofectamine 2000 reagent, following protocol of the manufacturer. The following day, cells were harvested in PBS containing $1 \mathrm{~mm}$ EDTA, divided, and replated at a lower density. Twenty-four hours later, cells were harvested again, resuspended in PBS containing $1 \mathrm{mg} / \mathrm{ml} \mathrm{BSA}$ and $1 \mathrm{mg} / \mathrm{ml}$ glucose, and adjusted to a final concentration of $\sim 1 \times 10^{6}$ cells $/ \mathrm{ml}$. Using ${ }^{125} \mathrm{I}-\mathrm{NGF}$ concentrations ranging from 0.01 to $2 \mathrm{nM}$, each condition assessed in triplicate in the presence and absence of excess $(500 \times)$ unlabeled NGF, equilibrium binding proceeded for $2 \mathrm{hr}$ at $4^{\circ} \mathrm{C}$. Cell-bound NGF was separated from free NGF by centrifugation through a cushion of calf serum. The specific counts averaged $60-85 \%$ of the total counts. The Scatchard plot analysis was performed and analyzed using the PRISM program as described previously (Mahadeo et al., 1994; Esposito et al., 2001). A nonlinear regression analysis was performed to directly compare curve fits to determine whether they were similar with $95 \%$ confidence limits.

\section{Results}

\section{The NRH2 protein}

The predicted structure of mouse NRH2 does not contain the extracellular cysteine-rich repeats characteristic of the TNF receptor family but does contain a consensus death domain at the C-terminal region (Fig. $1 A$ ). The NRH2 transmembrane domain 
A

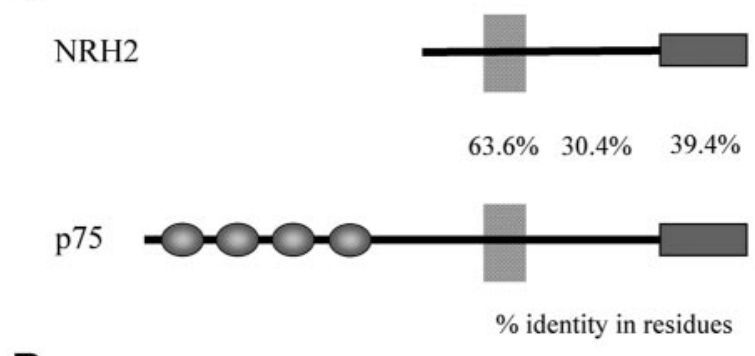

B

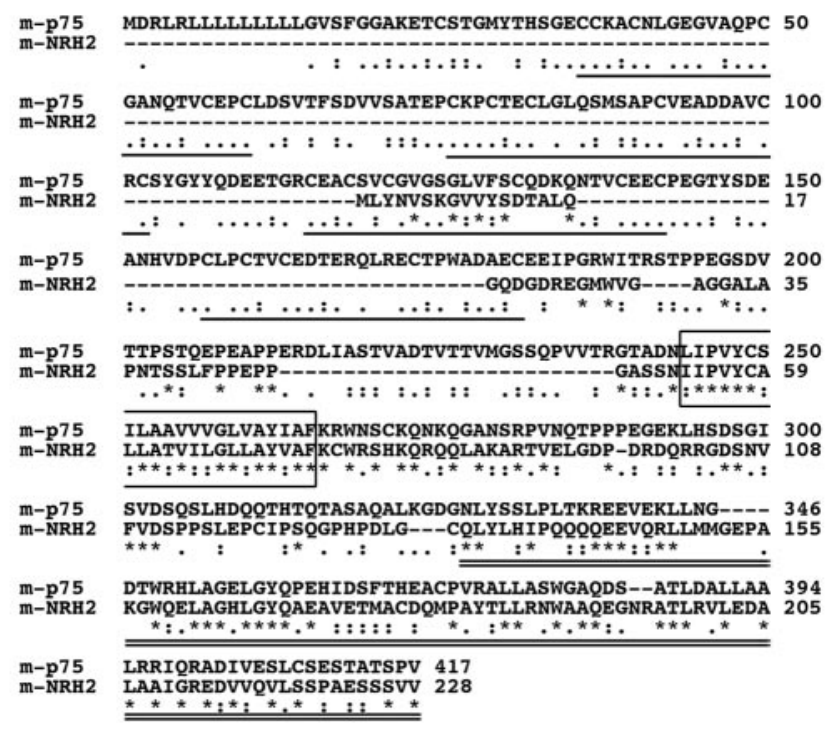

C

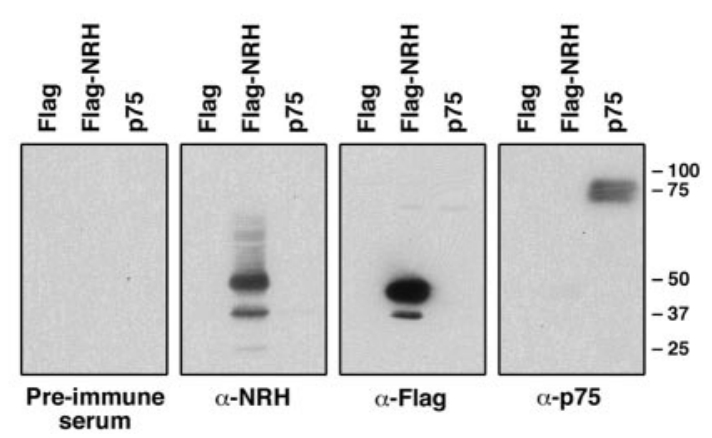

Figure 1. NRH2 protein structure. A, Diagramatic representation of $\mathrm{p} 75^{\mathrm{NTR}}$ and NRH2. Sequence similarity is high in the transmembrane, juxtamembrane, and death domain regions but dissimilar outside these regions. NRH2 contains a truncated extracellular domain that does not contain the cysteine repeating elements that are the defining feature for the tumor necrosis factor receptor family. The numbers represent percentage identity in amino acid residues for each region. $B$, ClustalW alignment of $p 75$ NTR and NRH2. Global alignment of full-length amino acid sequences of mouse p75 NTR (GenBank accession number AF105292) and mouse NRH2. Aligned using the default settings for the ClustalW program from the European Bioinformatics Institute (http://www.ebi.ac.uk/clustalw/). The repeating cysteine elements in p $75^{\mathrm{NTR}}$ are underlined, the transmembrane regions are boxed, and the death domains are double underlined. Consensus symbols are as follows: asterisks indicate that the residues are identical; colons indicates that conserved physiochemical substitutions are observed; and periods indicate that semiconserved substitutions are observed. C, Anti-NRH2 Western blot. The anti-NRH2 antibody is specific to the NRH2 protein. In Western blot analysis of transfected HEK293 whole-cell lysates, the anti-NRH2 antibody specifically detected NRH2 and did not cross-react with p75 NTR (second panel from left). Similarly, the p $75^{\mathrm{NTR}}$ antibody (9992, also directed against the intracellular domain) was specific to $\mathrm{p} 75^{\mathrm{NTR}}$ and did not cross-react with NRH2 (right panel). Preimmune serum and anti-Flag antibodies were used as controls. The doublet present in detecting NRH2 most likely represents differential extracellular glycosylation. is $64 \%$ identical, and the first 18 juxtamembrane residues are $50 \%$ identical to $\mathrm{p} 75^{\mathrm{NTR}}$. A higher degree of similarity exists between p $75^{\text {NTR }}$ and NRH2 in these regions than in the extracellular sequence or the C-terminal death domain (Fig. $1 B$ ). This comparison is significant, because the most highly conserved regions of p $75^{\text {NTR }}$ are the transmembrane and juxtamembrane sequences (Large et al., 1989; Hutson and Bothwell, 2001).

To determine whether the NRH2 protein is expressed in neurotrophin-responsive tissues, we generated a polyclonal antibody against the cytoplasmic domain of NRH2 (1074 antibody). This antibody was specific for NRH2 protein and did not recognize $\mathrm{p} 75^{\mathrm{NTR}}$ sequences in Western blot analysis (Fig. 1C). Also, the antisera raised against the cytoplasmic domain of $\mathrm{p} 75^{\mathrm{NTR}}$ (9992 antibody) did not cross-react with NRH2 in parallel Western blots.

\section{Neuronal expression of NRH2}

The expression of NRH2, a novel protein with homology to the p75 neurotrophin receptor, has not been investigated extensively. To begin to examine the expression profile of NRH2, neonatal rat retina, spinal cord, and DRG were sectioned and immunostained with the antibody made against the intracellular domain of NRH2 (1074 antibody). These tissues were also immunostained with an antibody made against the extracellular domain of the p75 receptor (9651 antibody) and an antibody that detects all Trk receptors (the pan-Trk C-14 antibody; Santa Cruz Biotechnology). Using the NRH2 antibody, immunoreactivity was detected in neuronal cells that also express $\mathrm{p} 75^{\mathrm{NTR}}$ and Trk receptors.

Within the neonatal rat retina NRH2, $\mathrm{p} 75^{\mathrm{NTR}}$ and Trk receptor immunoreactive neurons could all be detected. NRH2 immunoreactivity was present in a layered manner in the developing retina. Prominent NRH2 immunoreactivity was detected in the ganglion cell and inner nuclear layers, whereas the layer of optic nerve fibers and inner plexiform layer were clearly not stained. The eye is not fully differentiated at this time, and the cellular layers are still migrating; however, there is clear NRH2 immunoreactivity in the deeper progenitor layer that will eventually differentiate into the outer layers of the retina. The retinal pigment epithelium was also prominently stained with NRH2 (Fig. 2A). Trk immunoreactivity was also detected in the developing ganglion cell and inner nuclear layers, the same layers that express $\mathrm{NRH} 2$, but was absent in other areas (Fig. 2 B). Immunoreactivity to $\mathrm{p} 75^{\mathrm{NTR}}$ was also detected but did not overlap with NRH2 and Trk expression in the ganglion cell and inner nuclear layers. p $75^{\text {NTR }}$ expression was most prominent in the deeper progenitor layer (Fig. 2C). Sections stained with the preimmune serum from the NRH2 antibody produced no staining (Fig. 2D). Both Trk and $\mathrm{p} 75^{\mathrm{NTR}}$ receptor expression has been detected and found to be highly dynamic in the developing and mature retina (Nag and Wadhwa, 1999; Hutson and Bothwell, 2001). In particular, TrkA, TrkB, and TrkC immunoreactivity has been detected in the inner part of the neuroblastic layer, ganglion cell layer, and inner nuclear layer during early postnatal retinal development in mice (Llamosas et al., 1997). Therefore, there is overlapping expression of Trk receptors and NRH2 in specific neuronal populations within the postnatal retina and only partially overlapping and frequent discordant expression of Trk and p $75^{\mathrm{NTR}}$.

Within the neonatal rat spinal cord, NRH2 (Fig. 2E) and Trk (Fig. $2 F$ ) immunoreactivity could be clearly detected in spinal motor neurons. TrkB and TrkC receptor expression has been well documented in these neurons both during development and postnatally (Ernfors et al., 1993). In contrast, p75 ${ }^{\text {NTR }}$ expression in motor neurons is highly developmentally regulated and is rap- 

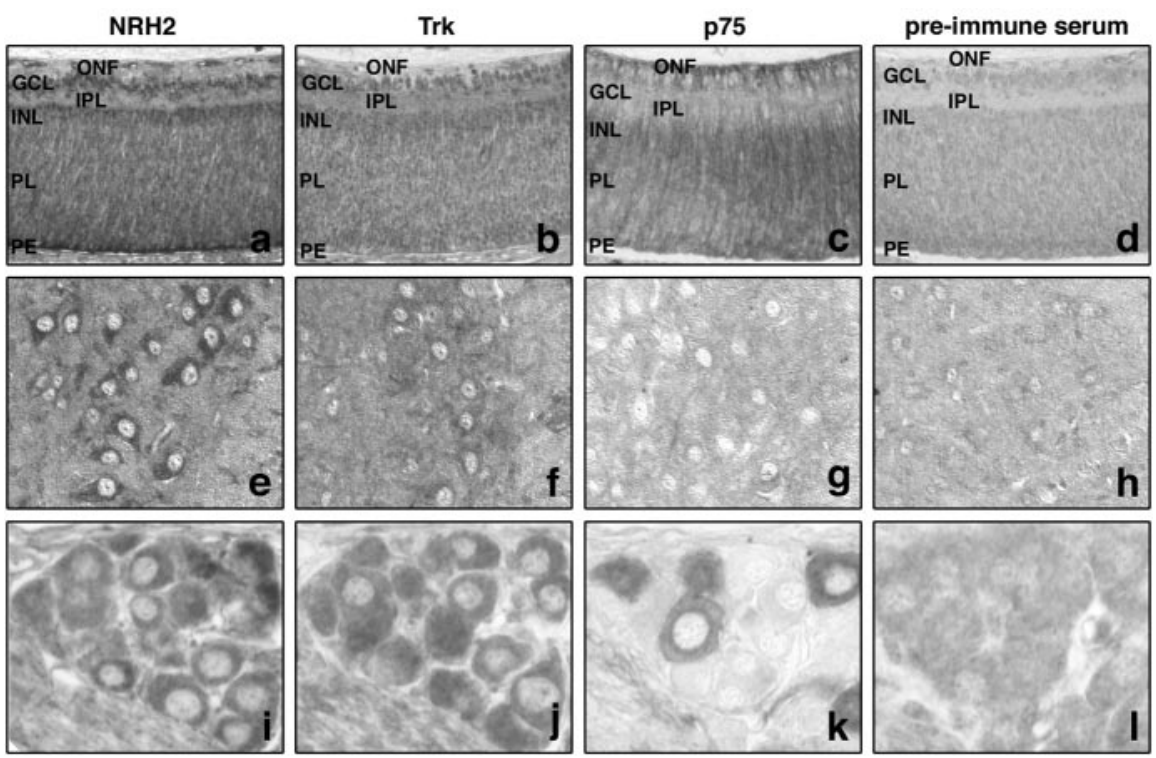

Figure 2. Expression of NRH2 in vivo. Expression of NRH2 in the neonatal rat retina, spinal cord, and DRG. Paraffin embedded tissues were subjected to indirect immunohistochemistry with the newly generated rabbit polyclonal anti-NRH2 (1074) antibody, as well as the anti-p75 (9651) antibody and pan-Trk (C-14; Santa Cruz Biotechnology) antibody. A-D, NRH2 immunoreactivity is detected within the ganglion cell layer (GCL), the inner nuclear layer (INL), and the pigment epithelium (PE) of the neonatal retina. The layer of optic nerve fibers (ONF) and inner plexiform layer (IPL) is not stained $(A)$. Comparison with Trk expression $(B)$ reveals that Trk receptors also expressed in the ganglion cell and inner nuclear layers. In contrast, these cells do not express p $75^{\text {NTR }}(C)$. However, both $\mathrm{p} 75^{\mathrm{NTR}}$ and NRH2 immunoreactivity is detected in the progenitor layer (PL) of the neonatal retina that will form the outer layers of the mature retina $(A, C$. Tissues incubated with $\mathrm{NRH} 2$ preimmune serum did not show any staining $(D)$. $E-H$, Neonatal rat spinal motor neurons express $\mathrm{NRH} 2(E)$ and Trk receptors $(F)$. No immunoreactivity to $\mathrm{p} 75^{\mathrm{NTR}}$ could be detected $(G)$. Incubation with preimmune serum is non-reactive $(H) . I-L, N R H 2$ immunoreactivity is detected within the majority of DRG sensory neurons $(/)$ and is seen to colocalize with Trk-expressing sensory neurons in adjacent sections $(/)$. p75 ${ }^{\text {NTR }}$ immunoreactivity is detected within a smaller subset of DRG neurons $(K)$. Incubation with preimmune serum produced no specific staining $(L)$.
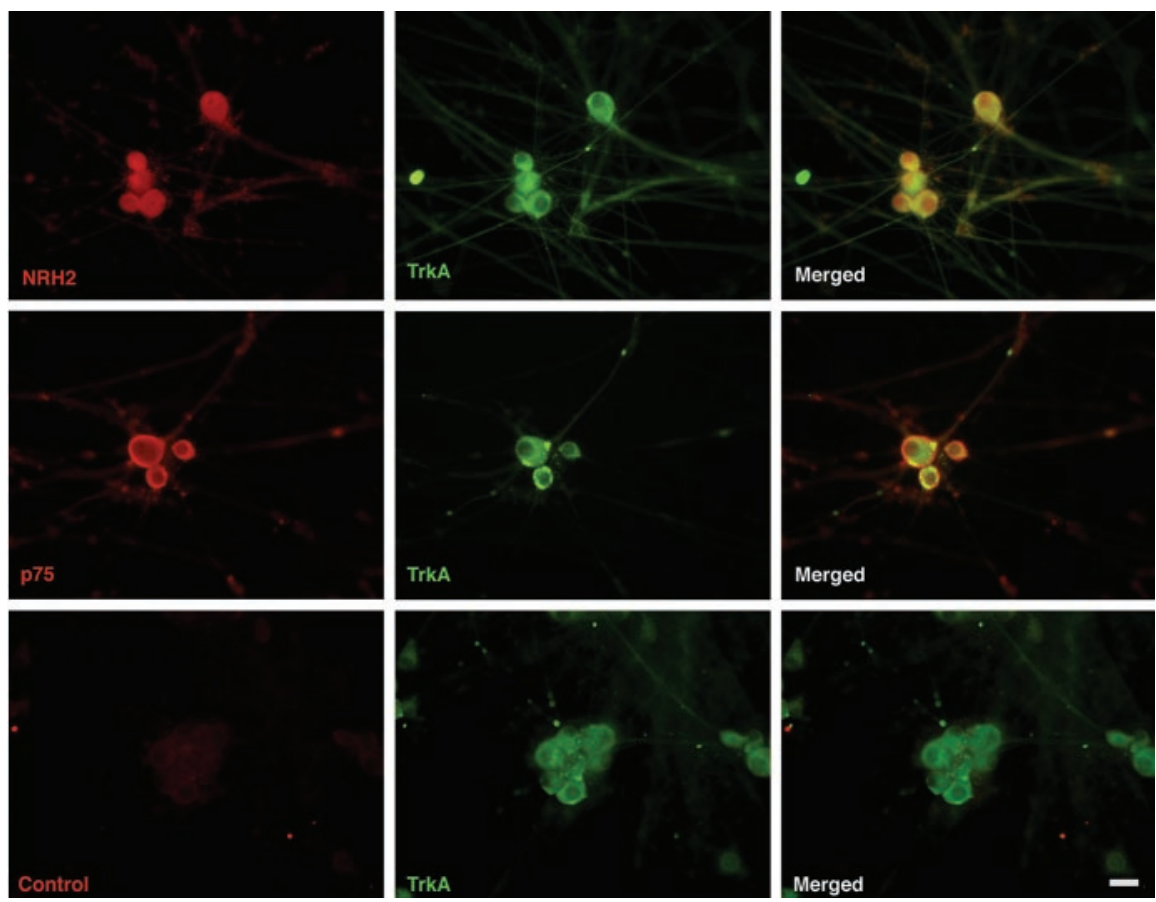

Figure 3. Expression of $\mathrm{NRH} 2$ in vitro. Expression of $\mathrm{NRH} 2$ in cultured neonatal mouse sympathetic neurons. Primary cell cultures in vitro were subjected to indirect immunocytochemistry with the rabbit polyclonal anti-NRH2 (1074) antibody, as well as the anti-p75 (9651) antibody and the monoclonal TrkA-specific (B3; Santa Cruz Biotechnology) antibody. Top row, NRH2 (left) and TrkA (middle) immunoreactivity is detected within primary sympathetic neurons and are shown to overlap (right). Middle row, Similarly, p75 NTR (left) and TrkA (middle) immunoreactivity is also detected and shown to overlap (right). Bottom row, Staining with NRH2 preimmune serum (left) did not show any staining. Scale bar, $20 \mu \mathrm{m}$. idly downregulated postnatally (Rende et al., 1992). In concordance with this, no immunoreactivity could be detected in these motor neurons using the $\mathrm{p} 75^{\mathrm{NTR}}$ antibody (Fig. 2G), whereas incubation with rabbit preimmune serum yielded no staining (Fig. $2 \mathrm{H}$ ). Here we show again clear evidence of the overlapping expression of Trk receptors and NRH 2 in the absence of p $75^{\text {NTR }}$. The expression of NRH2 in neurons that have recently downregulated p $75^{\text {NTR }}$ may indicate redundant function between these two proteins.

In the sensory neurons of the DRG, NRH2 (Fig. 2I) and Trk (Fig. 2J) were prominently expressed in the majority of neurons. Figure 2, I and $J$, represents 5 - $\mu \mathrm{m}$-thick adjacent sections in which the same neurons can be detected in both sections. Close examination reveals that NRH2 and Trk are coexpressed in a subset of DRG neurons. Neurons immunoreactive to $\mathrm{p} 75^{\mathrm{NTR}}$ are also detected within the DRG (Fig. $2 \mathrm{~K}$ ); however, fewer neurons are stained. A large proportion $(\sim 80 \%)$ of DRG sensory neurons express TrkA at this time in development, whereas only 50\% express p75 ${ }^{\text {NTR }}$ (Bennett et al., 1996). Our data indicates that NRH2 is also expressed in a large proportion of sensory neurons at this developmental stage. In a subpopulation of sensory neurons, NRH2 coexpression with Trk receptors was observed. Interestingly, coexpression of Trk receptors and $\mathrm{p} 75^{\mathrm{NTR}}$ has also been detected in sensory neurons (Wright and Snider, 1995). These results indicate that NRH2 is expressed in neurotrophin-responsive neurons in the peripheral nervous system. Significantly, NRH2 is found in cells that also express Trk receptors in the absence of p75 ${ }^{\text {NTR }}$ expression.

To further analyze NRH2 expression, specifically in respect to TrkA coexpression, primary cultures of mouse sympathetic neurons were generated in vitro. $\mathrm{NRH} 2$ expression was detected in all sympathetic neurons stained and is shown to colocalize with TrkA receptors (Fig. 3, top row). Interestingly, $\mathrm{p} 75^{\mathrm{NTR}}$ is also expressed and colocalized to $\operatorname{Trk} A$ in these neurons (Fig. 3, middle row), indicating that NRH2, p75 ${ }^{\mathrm{NTR}}$, and TrkA are all coexpressed in this neurotrophin-responsive neuronal population. Neurons stained with preimmune serum from the rabbit inoculated against NRH2 produced no staining (Fig. 3, bottom row).

\section{Cross-linking of ${ }^{125} \mathrm{I}-\mathrm{NGF}$ to $\mathrm{p} 75^{\mathrm{NTR}}$ - and NRH2-expressing cells}

NGF binds specifically to the four cysteine-rich repeating elements in the ex- 


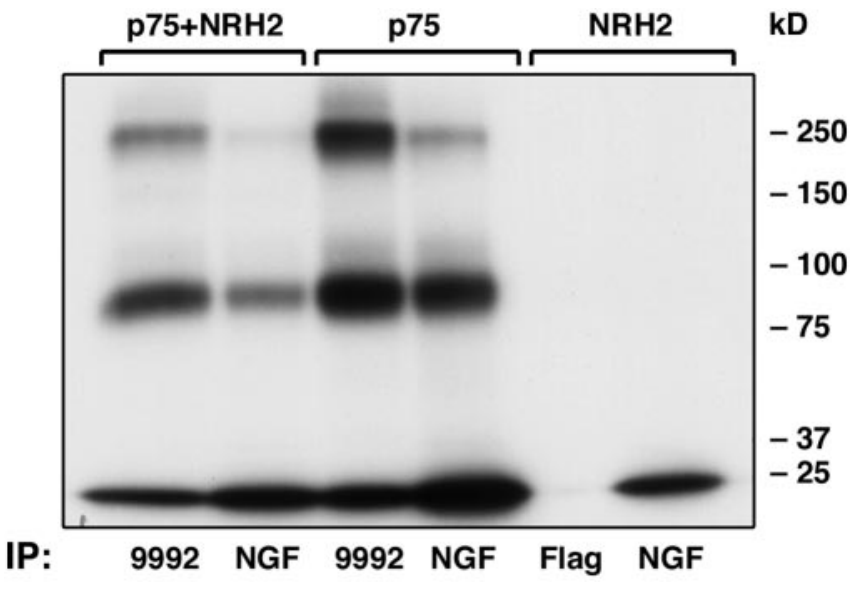

Figure 4. Affinity cross-linking of ${ }^{125}$ I-NGF to $775^{\text {NTR }}$ and NRH2. HEK293 cells were transfected with cDNAs encoding full-length p $75^{\mathrm{NTR}}, \mathrm{N}$-terminal Flag-tagged NRH2, or both constructs. Cells were subjected to both DSS and EDAC cross-linking in the presence of ${ }^{125}$ I-NGF. Cell lysates were then immunoprecipitated with anti-Flag, anti-p75 (9992), or anti-NGF antibodies, separated by SDS-PAGE, and subjected to autoradiography. ${ }^{125}$ I-NGF is cross-linked to the p75 receptor in two stoichiometries, as a monomer of $\sim 90 \mathrm{kDa}$ and as a dimer of $\sim 210 \mathrm{kDa}$ (Mahadeo et al., 1994). No cross-linking was detectable from cells expressing NRH2 alone (right lanes). In cells expressing both p75 NTR and NRH2, the NGF cross-linking profile was similar to cells expressing $\mathrm{p} 75^{\mathrm{NTR}}$ alone.

tracellular domain of p75 ${ }^{\text {NTR }}$ (Yan and Chao, 1991; Baldwin et al., 1992). NRH2 is unusual in that its extracellular domain lacks these repeating cysteine-rich motifs. Moreover, the 52 amino acids in the NRH2 extracellular domain display a lower similarity to p $75^{\text {NTR }}$ than the cytoplasmic sequence (Fig. 1). To investigate whether this extracellular sequence displays any binding to NGF, an affinity cross-linking experiment was performed. ${ }^{125} \mathrm{I}-\mathrm{NGF}$ could be easily cross-linked to the p75 receptor in a species of $\sim 90$ and $210 \mathrm{kDa}$ (Fig. 4). The $90 \mathrm{kDa}$ species corresponds to p $75^{\text {NTR }}$ cross-linked with ${ }^{125} \mathrm{I}-\mathrm{NGF}$, and the $210 \mathrm{kD}$ a presumably reflects a complex of p75 ${ }^{\mathrm{NTR}}$ dimers with ${ }^{125} \mathrm{I}-\mathrm{NGF}$ (Mahadeo et al., 1994). No cross-linked products were detectable from cells expressing NRH2 (right lanes). Furthermore, in cells expressing both $\mathrm{p} 75^{\mathrm{NTR}}$ and NRH2, the NGF cross-linking profile was similar to cells expressing p $75^{\text {NTR }}$ alone. Therefore, NRH2 does not exhibit specific binding to NGF as assessed by affinity cross-linking.

\section{Association of NRH2 with the Trk receptor}

Given that the p75 neurotrophin receptor interacts with the Trk receptors (Huber and Chao, 1995; Gargano et al., 1997; Bibel et al., 1999), we investigated whether NRH2 was capable of forming a similar association. An epitope-tagged NRH2 construct and full-length TrkA, TrkB, and TrkC cDNAs were transfected into HEK293 cells. Western blot analysis indicated that all proteins were expressed after transfection. Immunoprecipitation of NRH2 followed by Western blotting with an anti-pan Trk (C-14; Santa Cruz Biotechnology) antibody (Clary et al., 1994) indicated that NRH2 could be found in a complex with all three Trk receptors (Fig. 5A).

To determine the region within the Trk receptor that is required for the interaction with $\mathrm{NRH} 2$, additional coimmunoprecipitation experiments were performed with a series of deletion mutants. We used cytoplasmic deletions of the TrkA receptor that lacked the tyrosine kinase domain and sequences in the juxtamembrane region (Yano et al., 2001). Full-length Flag-tagged $\mathrm{NRH} 2$ was coexpressed in HEK293 cells and then subjected to immunoprecipitation and association with TrkA. Deletion of the tyrosine kinase domain of TrkA did not affect the association with NRH2. Hence, the TrkA juxtamembrane region [TrkA (1513)] was capable of binding to NRH2 (Fig. 5B). The additional deletion of 70 amino acids [TrkA (1-484), TrkA (1-463), and TrkA (1-443)] did not abolish the association with NRH2. These coimmunoprecipitation results suggest that the TrkA interaction with $\mathrm{NRH} 2$ is mediated by a region within the transmembrane domain and the first 10 juxtamembrane residues of the Trk receptor (Fig. 5C). This juxtamembrane region includes the highly conserved "KFG" amino acid sequence present in all Trk receptors (Peng et al., 1995; Kaplan and Miller, 1997). The NRH2TrkA interaction may alternatively be mediated through the TrkA transmembrane domain, as is suggested by the fact that p75 ${ }^{\text {NTR }}$, which also associates with Trk receptors, possesses a transmembrane domain that is very similar in sequence to that of NRH2 (Fig. 1) (Esposito et al., 2001).

\section{Effect of NRH2 on NGF binding}

The coexpression of NRH2 and Trk receptors in sympathetic neurons and sensory neurons of the dorsal root ganglion raises the possibility that $\mathrm{NRH} 2$ may exert an influence on Trk receptor function. The three Trk receptors are expressed by distinct sensory neuron populations in the dorsal root ganglion (Wright and Snider, 1995). It is well established that competition among neurons for limiting amounts of neurotrophins contributes to the number of surviving cells during development. The ability of Trk and 75 receptors to produce different binding sites and affinities can determine both neurotrophin responsiveness and specificity. One possibility is that NRH2 might alter the binding properties of neurotrophins. In fact, expression of $\mathrm{p} 75^{\mathrm{NTR}}$ is known to increase the binding affinity of NGF for TrkA. This effect is dependent on the transmembrane and cytoplasmic domains of $\mathrm{p} 75^{\mathrm{NTR}}$, which account for an increased rate of ligand association (Mahadeo et al., 1994) and copatching of Trk receptors (Wolf et al., 1998).

To examine the effect on NGF binding, TrkA and NRH2 cDNAs were transiently expressed in HEK293 cells, which do not express TrkA or NRH2 proteins endogenously. The conditions used for the transfection provided the adequate levels of receptors for equilibrium binding studies (Fig. 6), because cells overexpressing TrkA, such as the PC12 cell line 615, may result in increased receptor dimerization and thus a small number of highaffinity sites (Jing et al., 1992). Exposure of TrkA-transfected HEK293 cells to increasing concentrations of ${ }^{125}$ I-NGF produced a $K_{\mathrm{d}}$ of $1.4 \times 10^{-9} \mathrm{M}$, consistent with previous measurements (Fig. 6A) (Hempstead et al., 1991; Mahadeo et al., 1994; Schropel et al., 1995). When NRH2 was coexpressed with TrkA, a two-site Scatchard plot was generated, with an additional higher-affinity binding site of $K_{\mathrm{d}}$ of $4.0 \times 10^{-11} \mathrm{M}$ (Fig. $6 \mathrm{~B}$ ). Hence, NGF binding to TrkA could be enhanced by the expression of NRH2. However, consistent with the previous affinity cross-linking results (Fig. 4), binding of NGF to NRH2 does not occur. Instead, the transmembrane and cytoplasmic domains of NRH2 likely contribute to the increased binding affinity of NGF to TrkA. This conclusion is consistent with previous experiments with TrkA and $\mathrm{p} 75^{\mathrm{NTR}}$, in which a mutant $\mathrm{p} 75$ receptor incapable of binding to NGF could nevertheless enhance TrkA binding affinity (Esposito et al., 2001). Hence, NRH2 can produce an effect on neurotrophin binding even in the absence of cysteine-rich ligand binding domains. 
A

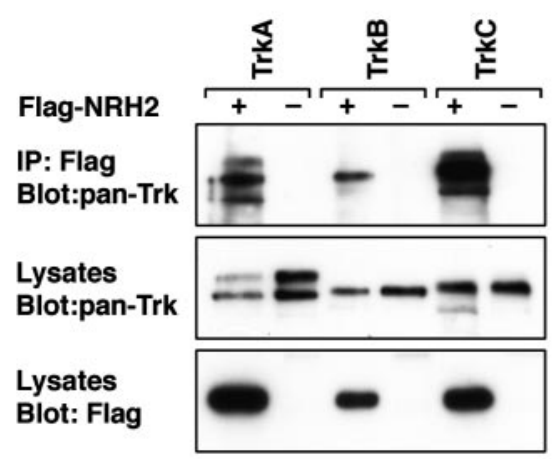

C

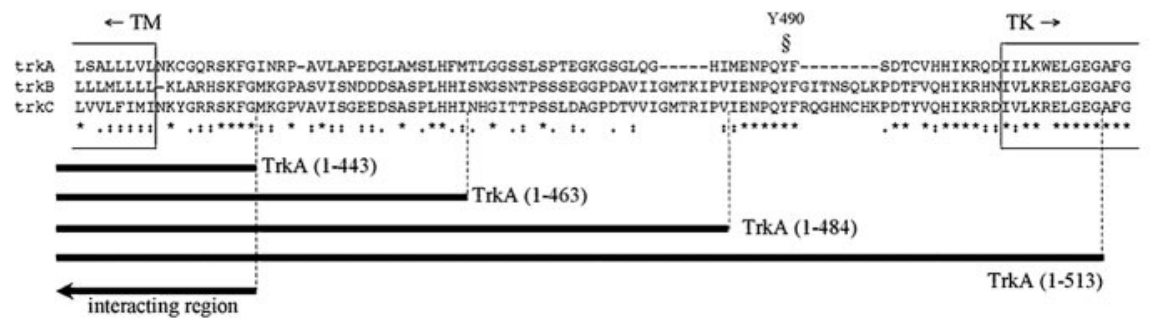

Figure 5. Association between NRH2 and Trk receptors. A, Association of NRH2 with TrkA. HEK293 cells were cotransfected with cDNAs encoding the full-length TrkA, TrkB, or TrkC and an N-terminal Flag-tagged NRH2 construct or empty Flag vector. Cell lysates were immunoprecipitated with anti-Flag antibodies and immunoblotted with the anti-pan Trk (C-14; Santa Cruz Biotechnology) antibody (top panel). Crude lysates were also immunoblotted with the (-14 antibody to confirm expression of Trk receptors (middle panel), stripped, and reprobed with an anti-Flag antibody to confirm equivalent expression level of NRH2 (bottom panel). B, Mapping the interaction of TrkA with NRH2. HEK293 cells were cotransfected with Flag-tagged NRH2 CDNA and full-length TrkA, TrkA truncation mutants, or vector alone. Whole-cell lysates were immunoprecipitated with anti-Flag antibodies and immunoblotted with anti-TrkA (AB1577; Chemicon) (top panel). Expression of the full-length and deletion constructs of TrkA was verified in crude cell lysates with the TrkA antibody (middle panel), as was NRH2 with the Flag antibody (bottom panel). C, Diagramatic representation of the TrkA mutants. Diagrammatic representation of the region that NRH2 maps to on TrkA. Also shown is the sequence similarity among rat TrkA, TrkB, and TrkC within this region. TM, Transmembrane domain; TK, kinase domain; Y490, Shc binding site

\section{Discussion}

Neurotrophin expression levels are critically important in determining the number of surviving and apoptotic cells in distinct neuronal and non-neuronal populations during development. Responsiveness to the neurotrophins, in turn, is dependent on the relative receptor binding affinity and resulting signaling events. The ability to generate high-affinity binding sites is functionally critical for neurons to avoid programmed cell death during competition for limiting amounts of trophic factors. The ratio of TrkA and p75 receptors is a critical parameter in the formation of high-affinity neurotrophin binding sites (Chao and Hempstead, 1995; Chao and Bothwell, 2002). This regulatory mechanism provides the ability of neurons to respond to neurotrophins in a cell-type-specific manner.

In this study, we found that the $\mathrm{NRH} 2$ protein possesses the ability to directly influence NGF binding to the TrkA receptor. These results were obtained by coexpressing full-length NRH2 with TrkA in transfected cells. Significantly, this ability did not rely on neurotrophin binding to NRH2 but is dependent on the transmembrane and cytoplasmic domains of NRH2. These measurements verified previous studies showing that the p75 and Trk receptors bind NGF with similar equilibrium binding constants (Hempstead et al., 1991; Schropel et al., 1995). NGF exhibits two different classes of binding sites based on equilibrium binding studies (Sutter et al., 1979). One way to achieve a high-affinity binding site is through the coexpression of TrkA and p75 receptors (Hempstead et al., 1991). When coexpressed, the TrkA-p75 receptor complex exhibits higher-affinity NGF binding constants $\left(K_{\mathrm{d}}\right.$ of $\left.10^{-11} \mathrm{M}\right)$ than those exhibited by each receptor alone. Here we showed that $\mathrm{NRH} 2$ also has the ability to increase NGF binding affinity. Similar to what has been found with p75 ${ }^{\text {NTR }}$ coexpression, NRH2 appears to act through its transmembrane and cytoplasmic sequences. As a consequence, the rate of association is accelerated (data not shown), generating a new kinetic site exhibiting high-affinity binding properties (Hempstead et al., 1991; Mahadeo et al., 1994).

NRH2 may influence Trk receptors through associated adaptor proteins that are involved in receptor aggregation. Alternatively, high levels of NRH2 in selective neuronal cells may alter Trk receptor conformation. Previous analysis using a series of deletion mutants, point mutants, and chimeric receptor constructs suggested that high-affinity neurotrophin binding is achieved by conformational changes that occur in the Trk receptor (Esposito et al., 2001). These changes may be transmitted through small changes in structure (Arevalo et al., 2001) or by dimerization (Arevalo et al., 2000).

To further support the view that NRH2 is an important component of neurotrophin signaling, we showed that $\mathrm{NRH} 2$ and Trk receptors are coexpressed in neuronal populations in the absence of $\mathrm{p} 75^{\mathrm{NTR}}$. The majority of NGF-responsive cells, including all sympathetic and basal forebrain cholinergic and some sensory neurons, express both $\mathrm{p} 75^{\text {NTR }}$ and TrkA. In addition to this, NRH2 and Trk receptors are coexpressed in sympathetic neurons and in spinal motor neurons and subsets of retinal and DRG sensory neurons when $\mathrm{p} 75^{\mathrm{NTR}}$ is not expressed. The presence of NRH2 in these neuronal cell types implies it may be a component of neurotrophin signaling. In addition, it is interesting to note that non-neuronal cells also express NRH2. For example, NRH2 protein is found in kidney, a site of both $\mathrm{p} 75^{\mathrm{NTR}}$ and Trk expression (data not shown) (Alpers et al., 1993; Huber et al., 1996).

The expression of p75 and TrkA receptors is highly regulated during neuronal development and in response to injury. The cytoplasmic portion of NRH2 contains a death domain sequence similar to the intracellular domains of $\mathrm{p} 75^{\mathrm{NTR}}$ and the Fas and p55 TNF receptors. In the case of p $75^{\mathrm{NTR}}$, several cases of ligandinduced cell death now exist (Hempstead, 2002), with these events being dependent on cell-specific interactions with adaptor proteins. In a similar manner, NRH2 may be critical in regulating both survival and apoptotic events either independently or through interactions with TrkA or $\mathrm{p} 75^{\mathrm{NTR}}$. In the presence of Trk, NRH2 may function to assist in the formation of highaffinity binding sites. Recent evidence suggests a role for a 

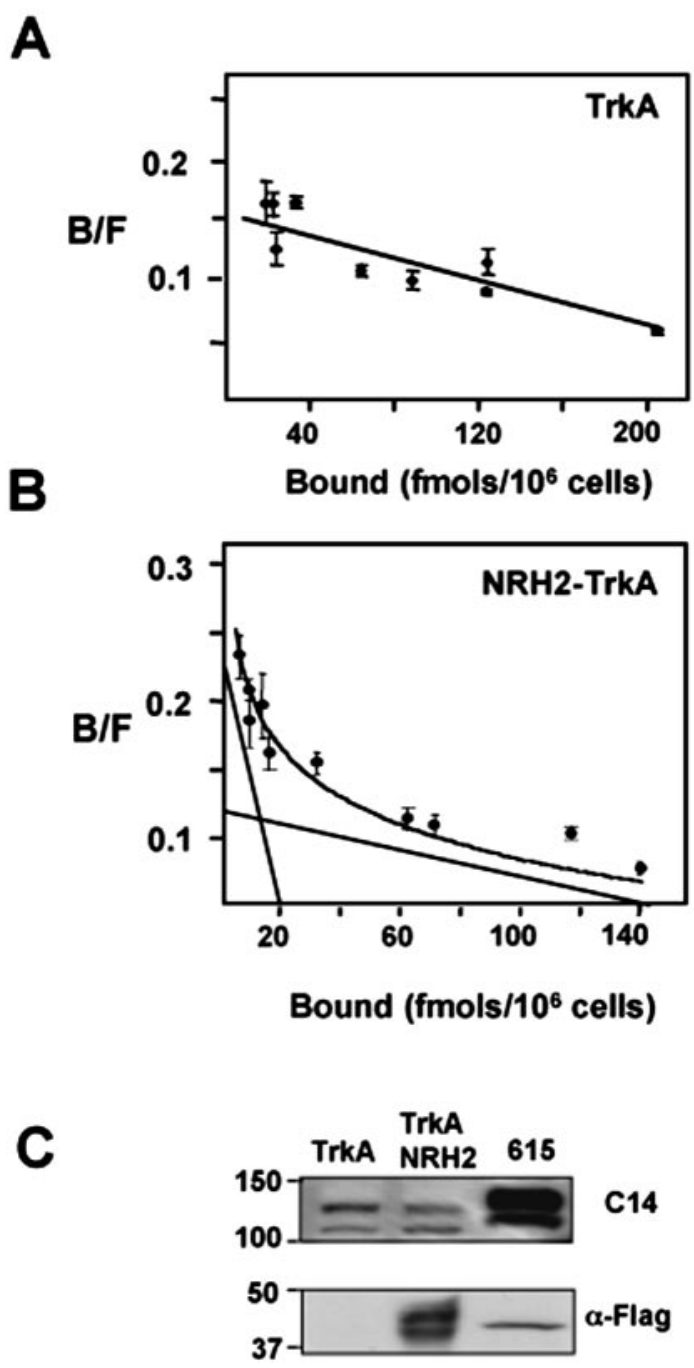

Figure 6. Coexpression of NRH2 and TrkA induces high-affinity NGF binding site formation. To assess a role of NRH2 in high-affinity site formation, full-length TrkA was transiently coexpressed in HEK293 cells with or without NRH2. Equilibrium binding of $\sim 1 \times 10^{6}$ transfected HEK293 cells expressing the indicated receptor constructs were incubated with increasing concentrations of ${ }^{125}$-labeled NGF $(0.01-2 \mathrm{~nm})$ in the presence or absence of excess unlabeled ligand. Values represent means of triplicate determinations of specific binding. $A$, Scatchard analysis of TrkA-transfected HEK293 cells to increasing concentrations of ${ }^{125}$-NGF produced a linear plot of $K_{d}$ of $1.4 \times 10^{-9} \mathrm{M}$. $B$, When NRH2 was coexpressed with TrkA, a two-site Scatchard plot was generated with an additional higher-affinity binding site of $K_{\mathrm{d}}$ of $4.0 \times$ $10^{-11}$ M. C, Western blot analysis to assess the expression of TrkA and NRH2 in whole-cell lysates of the transfected HEK293 cells. B/F, Bound/Free.

membrane-tethered form of $\mathrm{p} 75^{\mathrm{NTR}}$ in forming an association with TrkA (Jung et al., 2003). Trk receptors, therefore, may have the ability of forming multimeric complexes with $\mathrm{NRH} 2$ and full-length or cleaved forms of $\mathrm{p} 75^{\mathrm{NTR}}$. NRH2 may also be capable of independent signaling through proteins known to associate with $\mathrm{p} 75^{\mathrm{NTR}}$, because their cytoplasmic sequences display homology. Also, under conditions of nerve injury or stress, p $75^{\text {NTR }}$ is frequently upregulated (Dobrowsky and Carter, 2000). It will be of interest to study whether NRH2 is under similar regulation and whether it is directly involved in transmitting neurotrophic signals.

During the development of the nervous system, it has been proposed that $\mathrm{p} 75^{\mathrm{NTR}}$ influences the formation of high-affinity NGF binding sites in concert with Trk receptors. As a consequence, this increases responsiveness to NGF at specific stages of sensory neuron cell survival (Davies et al., 1993; Barrett and Bartlett, 1994) and increases the kinetics of neuronal cell maturation (Verdi et al., 1994). The finding of a new receptor gene related to p $75^{\mathrm{NTR}}$ suggests additional mechanisms to regulate $\mathrm{p} 75^{\mathrm{NTR}}$ and the Trk family of receptors during cellular differentiation and survival in many tissues.

\section{References}

Alpers CE, Hudkins KL, Ferguson M, Johnson RJ, Schatteman GC, Bothwell M (1993) Nerve growth factor receptor expression in fetal, mature, and diseased human kidneys. Lab Invest 69:703-713.

Arevalo J, Conde B, Hempstead B, Chao M, Martin-Zanca D, Perez P (2000) TrkA immunoglobulin-like ligand binding domains inhibit spontaneous activation of the receptor. Mol Cell Biol 20:5908-5916.

Arevalo J, Conde B, Hempstead B, Chao M, Martin-Zanca D, Perez P (2001) A novel mutation within the extracellular domain of TrkA causes constitutive receptor activation. Oncogene 20:1229-1234.

Baldwin AN, Bitler CM, Welcher AA, Shooter EM (1992) Studies on the structure and binding-properties of the cysteine-rich domain of rat low affinity nerve growth-factor receptor (p75ngfr). J Biol Chem 267:8352-8359.

Bamji S, Majdan M, Pozniak CD, Belliveau DJ, Aloyz R, Kohn J, Causing CG, Miller FD (1998) The p75 neurotrophin receptor mediates neuronal apoptosis and is essential for naturally occurring sympathetic neuron death. J Cell Biol 140:911-923.

Barrett GL, Bartlett PF (1994) The p75 receptor mediates survival or death depending on the stage of sensory neuron development. Proc Natl Acad Sci USA 91:6501-6505.

Bennett DL, Averill S, Clary DO, Priestley JV, McMahon SB (1996) Postnatal changes in the expression of the trkA high-affinity NGF receptor in primary sensory neurons. Eur J Neurosci 8:2204-2208.

Bibel M, Hoppe E, Barde Y (1999) Biochemical and functional interactions between the neurotrophin receptors trk and p75NTR. EMBO J 18:616-622.

Chao M, Bothwell M (2002) Neurotrophins: to cleave or not to cleave. Neuron 33:9-12.

Chao MV, Hempstead BL (1995) p75 and trk: a two receptor system. Trends Neurosci 19:321-326.

Clary DO, Weskamp G, Austin LR, Reichardt LF (1994) TrkA cross-linking mimics neuronal responses to nerve growth factor. Mol Biol Cell 5:549-563.

Davies A, Lee K-F, Jaenisch R (1993) p75 deficient trigeminal sensory neurons have an altered response to NGF but not to other neurotrophins. Neuron 11:1-20.

Dobrowsky RT, Carter BD (2000) p75 neurotrophin receptor signaling: mechanisms for neurotrophic modulation of cell stress? J Neurosci Res 61:237-243.

Ernfors P, Rosario CM, Merlio JP, Grant G, Aldskogius H, Persson H (1993) Expression of mRNAs for neurotrophin receptors in the dorsal root ganglion and spinal cord during development and following peripheral or central axotomy. Brain Res Mol Brain Res 17:217-226.

Esposito D, Patel P, Stephens R, Perez P, Chao M, Kaplan D, Hempstead B (2001) The cytoplasmic and transmembrane domains of the p75 and TrkA receptors regulate high affinity binding to nerve growth factor. J Biol Chem 276:32687-32695.

Frankowski H, Castro-Obregon S, del Rio G, Rao RV, Bredesen DE (2002) PLAIDD, a type II death domain protein that interacts with p75 neurotrophin receptor. Neuromolecular Med 1:153-170.

Gargano N, Levi A, Alema S (1997) Modulation of nerve growth factor internalization by direct interaction between p75 and TrkA receptors. J Neurosci Res 50:1-12.

Hempstead BL (2002) The many faces of p75NTR. Curr Opin Neurobiol 12:260-267.

Hempstead BL, Martin-Zanca D, Kaplan DR, Parada LF, Chao MV (1991) High-affinity NGF binding requires co-expression of the trk protooncogene and the low-affinity NGF receptor. Nature 350:678-683.

Huang E, Reichardt L (2001) Neurotrophins: roles in neuronal development and function. Annu Rev Neurosci 24:677-736.

Huber LJ, Chao MV (1995) A potential interaction of p75 and trkA NGF receptors revealed by affinity crosslinking and immunoprecipitation. J Neurosci Res 40:557-563. 
Huber LJ, Hempstead B, Donovan MJ (1996) Neurotrophin and neurotrophin receptors in human fetal kidney. Dev Biol 179:369-381.

Hutson LD, Bothwell M (2001) Expression and function of Xenopus laevis p75(NTR) suggest evolution of developmental regulatory mechanisms. J Neurobiol 49:79-98.

Jing SQ, Tapley P, Barbacid M (1992) Nerve growth-factor mediates signal transduction through trk homodimer receptors. Neuron 9:1067-1079.

Jung KM, Tan S, Landman N, Petrova K, Murray S, Lewis R, Kim PK, Kim DS, Ryu SH, Chao MV, Kim TW (2003) Regulated intramembrane proteolysis of the p75 neurotrophin receptor modulates its association with the TrkA receptor. J Biol Chem 11:42161-42169.

Kanning KC, Hudson M, Amieux PS, Wiley JC, Bothwell M, Schecterson LC (2003) Proteolytic processing of the p75 neurotrophin receptor and two homologs generates C-terminal fragments with signaling capability. J Neurosci 23:5425-5436.

Kaplan DR, Miller FD (1997) Signal transduction by the neurotrophin receptors. Curr Opin Cell Biol 9:213-221.

Kaplan DR, Miller FD (2000) Neurotrophin signal transduction in the nervous system. Curr Opin Neurobiol 10:381-391.

Khursigara G, Bertin J, Yano H, Moffett H, DiStefano P, Chao M (2001) A pro-survival function for the $\mathrm{p} 75$ receptor death domain mediated via the caspase recruitment domain receptor interacting protein 2. J Neurosci 21:5854-5863.

Large TH, Weskamp G, Helder JC, Radeke MJ, Misko TP, Shooter EM, Reichardt LF (1989) Structure and developmental expression of the nerve growth factor receptor in the chicken central nervous system. Neuron 2:1123-1134.

Llamosas MM, Cernuda-Cernuda R, Huerta JJ, Vega JA, Garcia-Fernandez JM (1997) Neurotrophin receptors expression in the developing mouse retina: an immunohistochemical study. Anat Embryol (Berl) 195:337-344.

Mahadeo D, Kaplan L, Chao MV, Hempstead BL (1994) High affinity nerve growth factor binding displays a faster rate of association than p140(trk) binding-implications for multisubunit polypeptide receptors. J Biol Chem 269:6884-6891.

Nag TC, Wadhwa S (1999) Neurotrophin receptors (Trk A, Trk B, and Trk
C) in the developing and adult human retina. Brain Res Dev Brain Res 117:179-189.

Peng X, Greene LA, Kaplan DR, Stephens RM (1995) Deletion of a conserved juxtamembrane sequence in Trk abolishes NGF-promoted neuritogenesis. Neuron 15:395-406.

Rende M, Hagg T, Manthorpe M, Varon S (1992) Nerve growth factor receptor immunoreactivity in neurons of the normal adult rat spinal cord and its modulation after peripheral nerve lesions. J Comp Neurol 319:285-298.

Roux PP, Barker PA (2002) Neurotrophin signaling through the p75 neurotrophin receptor. Prog Neurobiol 67:203-233.

Schropel A, von Schack D, Dechant G, Barde Y-A (1995) Early expression of the nerve growth factor receptor ctrkA in chick sympathetic and sensory ganglia. Mol Cell Neurosci 6:544-556.

Sutter A, Riopelle RJ, Harris-Warrick RM, Shooter EM (1979) NGF receptors: characterization of two distinct classes of binding sites on chick embryo snesory ganglia cells. J Biol Chem 254:5972-5982.

Verdi JM, Birren SJ, Ibanez CF, Persson H, Kaplan DR, Benedetti M, Chao MV, Anderson DJ (1994) p75(LNGFR) regulates trk signal transduction and NGF-induced neuronal differentiation in MAH cells. Neuron 12:733-745.

Wang X, Shao Z, Zetoune FS, Zeidler MG, Gowrishankar K, Vincenz C (2003) NRADD, a novel membrane protein with a death domain involved in mediating apoptosis in response to ER stress. Cell Death Differ 10:580-591.

Wolf D, McKinnon-Thompson C, Daou M, Stephens R, Kaplan D, Ross A (1998) Mobility of TrkA is regulated by phosphorylation and interactions with the low-affinity NGF receptor. Biochemistry 3:3178-3186.

Wright DE, Snider WD (1995) Neurotrophin receptor mRNA expression defines distinct populations of neurons in rat dorsal root ganglia. J Comp Neurol 351:329-338.

Yan H, Chao MV (1991) Disruption of cysteine-rich repeats of the p75 nerve growth factor receptor leads to loss of ligand binding. J Biol Chem 266:12099-12104.

Yano H, Lee F, Kong H, Chuang J-Z, Arevalo J, Perez P, Sung C-H, Chao M (2001) Association of tyrosine kinase neurotrophin receptors with components of the cytoplasmic dynein motor. J Neurosci 21:RC125(1-7). 